\title{
Adsorptive Removal of Direct-Red-28 Dye from Contaminated Water Using Subabool Timber Wood Waste
}

\author{
${ }^{* 1}$ Tripti B. Gupta, ${ }^{2}$ Sharda P. Siddh, ${ }^{3}$ Hariom P. Khungar
}

${ }^{1,2,3}$ Shri Ramdeobaba College of Engineering and Management, Nagpur

Email: ${ }^{1}$ guptatb@rknec.edu, ${ }^{2}$ siddhsp@rknec.edu, ${ }^{3}$ khungarhp@rknec.edu

Received: 22nd October 2019, Accepted: 20th November 2019, Published: 31st December 2019

\begin{abstract}
In the current exercise, laboratory batch tests were conceded out to inspect adsorptive removal competency of Direct-red-28 dye from the contaminated water under ideal conditions using Subabool timber wood waste as a sorbent substance. The Direct-red-28 dye effluents are considered to be awfully venomous and distress the bionetwork by disquieting the nature and by decreasing photosynthetic actions due to the colorization of the water. Outcomes of diverse characteristics like Subabool timber wood waste dosage effect, solute-solvent $\mathrm{pH}$ effect, Direct-red-28 dye concentration effect, adsorption temperature effect and contact duration effect were examined aiming to acquire the finest uptake confiscation capability of the Subabool timber wood waste. 3 graphical isotherms were chosen to explore laboratory practical data. The technique of adsorption is investigated by taking into account $1^{\text {st }}$ and $2^{\text {nd }}$ order kinetics. From the current exercise, it is observed that the Subabool timber wood waste can be selected for the adsorptive removal of Direct-red-28 dye from contaminated water.
\end{abstract}

Keywords

Batch, Direct-Red-28, Isotherms, Subabool Timber Wood Waste

\section{Introduction}

Water is one of the vital fluid on which all life depends. Its contamination has become important issue globally. We must treat water, as; it is one of the most valuable natural resource in the world. Today, litter in the form of water and its scarcity is the major concern. Due to uneconomical and ineffective water treatment, a lot of manufacturing and production industries discharge their contaminated water to nearby land or water sources without any processing or treatment [1]. Physico-chem adsorption is one among the majority of treatment systems. This system is more fruitful if the material used for adsorption is price efficient. Countless research has been conducted to understand the potential of alternating resources [2]. In this study, batch processes were conducted to scrutinize the prospect of Subabool timber wood waste as a sorbent for removal of Direct-red-28 dye from the contaminated water.

\section{Resources and Methodologies}

Subabool timber wood waste (STWW) is selected as an adsorbent in the current task. Acacia Glaucia is the technical nomenclature for the easily found perennial plant. The common nomenclature for this plant is "Subabool". Universal mark reagents are used in the current research work. Direct-red-28 dye (D-R-28 dye) is purchased from, Central Scientific Company, Nagpur. The master-stock of $1000 \mathrm{mg} / \mathrm{L}$ (ppm) and subsequentstock for every solutions were made by taking respective amount of reagent in distilled water. Parametric studies, batch programme, equilibrium studies and kinetic studies of Direct-red-28 dye were passed by means of the ideal procedure given in Indian standards code 1350:1984 [3].

\section{Results and Discussions}

1. Parametric Character Studies of STWW

Characters of STWW comprise parametric studies. Owed to existence of volatile-substance, STWW may be considered as organic in behavior.

\begin{tabular}{|c|c|c|c|c|}
\hline $\begin{array}{c}\text { Parametric character } \\
\text { studies }\end{array}$ & Water-content & Ash-residue & Volatile-substance & Fix-carbon \\
\hline STWW (\%) & 8.00 & 6.40 & 74.60 & 11.00 \\
\hline
\end{tabular}

Table 1: Parametric Character Studies of STWW

\section{Batch Studies}

In array of understanding the effect of diverse parameters the batch laboratory tests were conducted.

\subsection{STWW Dosage Effect}

The STWW dosage $(m)$ effect on the confiscation of D-R-28 dye by STWW at Direct-red-28 dye $C_{0}=50$ $\mathrm{mg} / \mathrm{L}$ is shown in Figure 1. It can be seen that the D-R-28 dye confiscation grows up-to some value followed by approximately stable. Most favorable $m$ was found to be $40 \mathrm{~g} / \mathrm{L}$ for STWW. Figure 1 shows that the $q_{e}$ reduces with boost in value of $m$. This could be because of saturation of adsorption area [4]. 


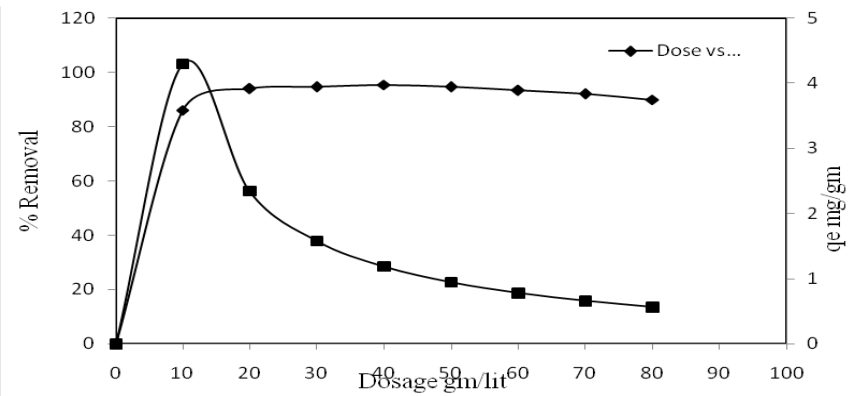

Fig 1: Dosage Effect of D-R-28 by STWW

\subsection{Solute-Solvent pH Effect}

The $\mathrm{pH}$ changes the shell value of the adsorbed material as well as the ion formation amount of the solutesolvents [5]. It is a pervasive surveillance from the Figure 2 that the shell adsorbs negative ions constructively at poorer $\mathrm{pH}$ due to incidence of $\mathrm{H}^{+}$ionized substances, while, the shell is dynamic for the adsorption of positive ions at elevated $\mathrm{pH}$ due to the affidavit of $\mathrm{OH}^{-}$ionized substances [6]. The D-R-28 color is roughly firm at around natural $\mathrm{pH}=6.92$ for STWW, all supplementary laboratory tests were considered at nature $\mathrm{pH}$ of 6.92 .

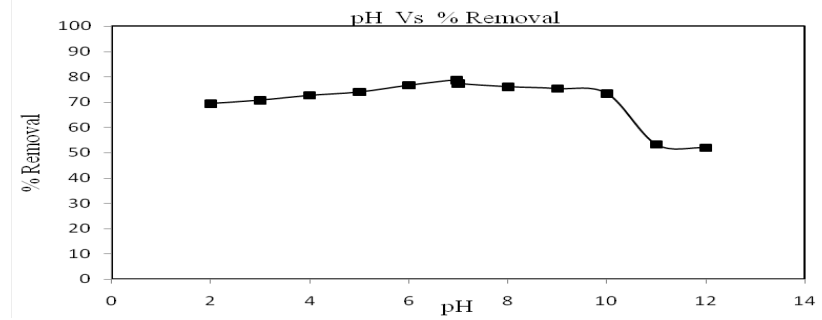

\subsection{Direct-Red-28 Dye Concentration Effect}

Fig 2: Solute-Solvent pH Effect of D-R-28 by STWW

The $C_{0}$ effect on the confiscation of D-R-28 dye by STWW shows that the amount of D-R-28 dye adsorbed per part mass of STWW $\left(q_{e}\right)$ enlarged with the boost in $C_{0}$, even though \% D-R-28 confiscation felled with the boost in $C_{0}$. Also the Figure 3 depicts that the adsorption of the D-R-28 boost up with reference to temperature that shows the endo-thermal mechanism.

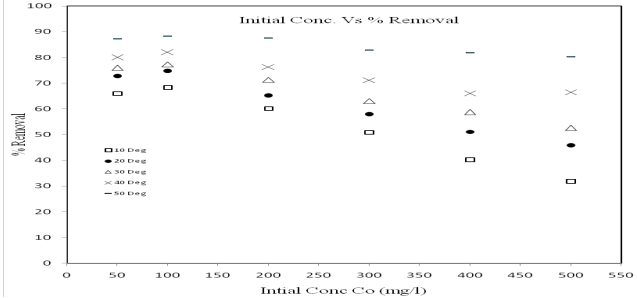

Fig 3: Concentration Effect of D-R-28 by STWW at $10^{\circ} \mathrm{C}$ to $50^{\circ} \mathrm{C}$

\subsection{Contact Duration Effect}

The contact duration $(t)$ plots shown in Figure 4 gives an idea about speedy adsorptive mechanism of D-R-28 in the earliest $30 \mathrm{~min}$, then, the adsorptive mechanism cataract step by step and the adsorption acquires symmetrical equilibrium in $3 \mathrm{~h}$. Figure 4 also states the singly, nonstop, smooth, and horizontal graphs stirring in the direction of diffusion. These graphs stipulate a doable single-layer coat of D-R-28 on the STWW seal [6]. The $\%$ confiscation is greatest at $3 \mathrm{~h}$ of contact duration that remnants steady later than this duration.

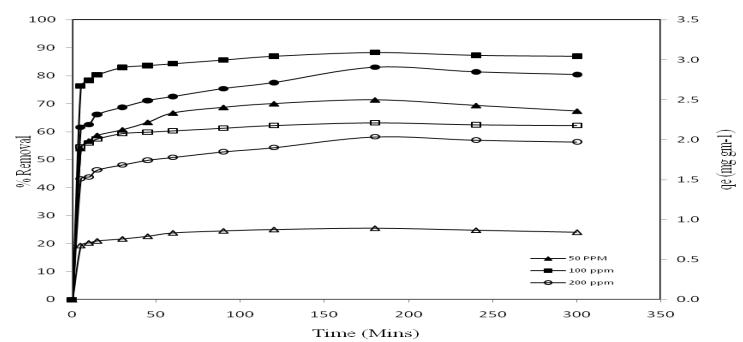

Fig 4: Contact Duration Effect on Adsorptive Mechanism of D-R-28 by STWW 
2.5. Adsorption Temperature Effect

Figure 5 represents the adsorptive mechanism of D-R-28 boost up with the raise in temperature. This raise characterize that the adsorptive mechanism might be as a result of chemisorbs [7]. Figure 5 also characterize that at poorer D-R-28 dye concentrations, qe raises piercingly and then rise is gradual with solute-solvent concentration.

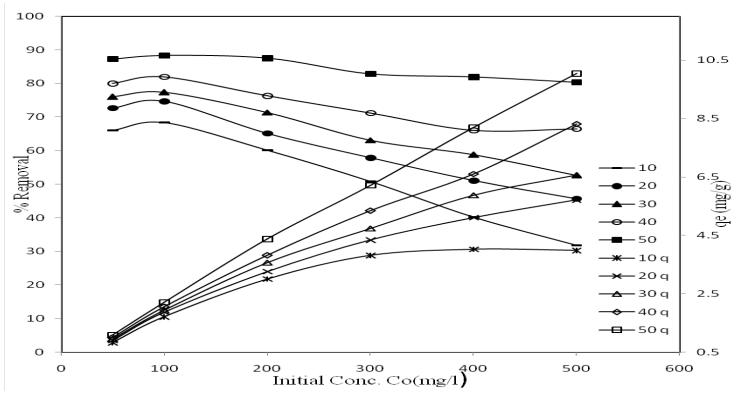

Fig 5: Temperature Effects of D-R-28 by STWW at $10^{\circ} \mathrm{C}$ to $50{ }^{\circ} \mathrm{C}$.

\section{Equilibrium Analysis}

Best fitting correspondence for the equilibrium graphs are analyzed so as to do optimization of adsorption mechanism. It is applied to diverse isotherm models like Langmuir [8], Freundlich [9] and Temkin [10] so as to express the stability and symmetrical characters of adsorption process.

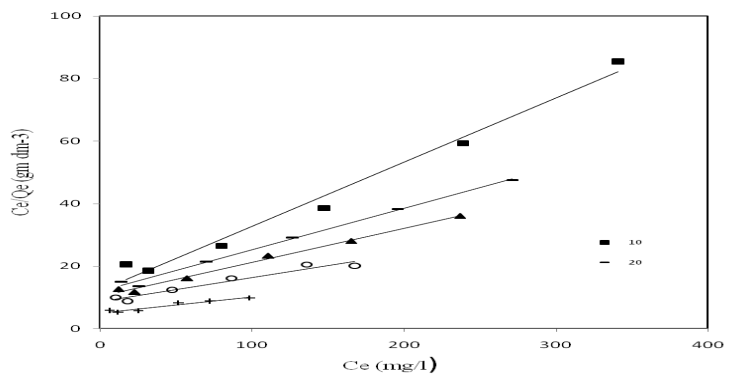

Fig 6: Langmuir Model for the Confiscation of D-R-28 at $10^{\circ} \mathrm{C}$ to $50^{\circ} \mathrm{C}$ by STWW

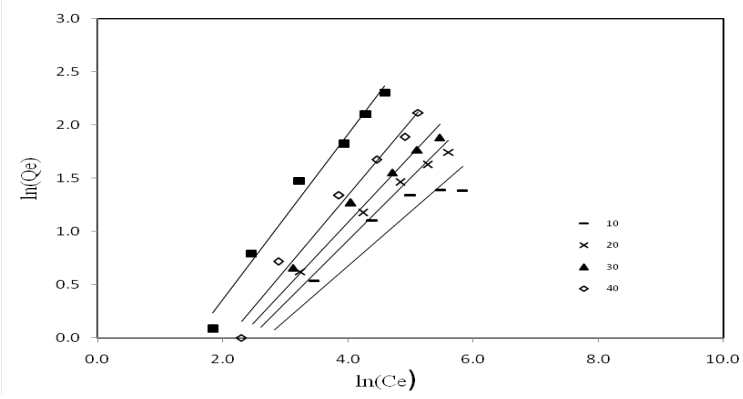

Fig 7: Freundlich Model for the Confiscation of D-R-28 at $10^{\circ} \mathrm{C}$ to $50^{\circ} \mathrm{C}$ by STWW

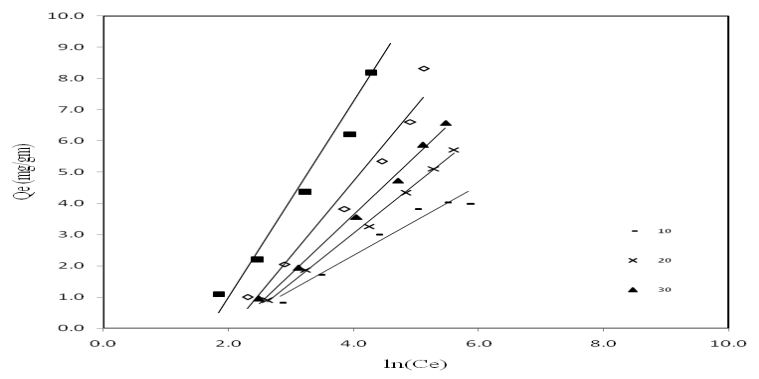

Fig 8: Temkin Model for the Confiscation of D-R-28 at $10^{\circ} \mathrm{C}$ to $50^{\circ} \mathrm{C}$ by STWW 
By doing assessment of the outcomes of the standards through diverse error functions, it is established that Langmuir model is best-fitted isotherm for confiscation of D-R-28 onto STWW at approximately every temperatures.

\section{4. $1^{\text {st }}$ and $2^{\text {nd }}$ Order Kinetics Analysis}

The kinetic analysis governs the solvent-solute adsorption rate, that go rounds and describes the residual contact duration of uptake [11]. It is 1 among the major feature, in governing the competence of uptake adsorption. The adsorptive mechanism of D-R-28 under an ideal condition adapts reversing $1^{\text {st }}$ kinetic order, after a sole class is selected on a hetero-assorted area. In this work, $1^{\text {st }}$ and $2^{\text {nd }}$ order kinetics analysis is conceded out in batches mode so as to get the technique of uptake. $1^{\text {st }}$ order Figure 9 and $2^{\text {nd }}$ order Figure 10 kinetic graphs have been plotted and observed.

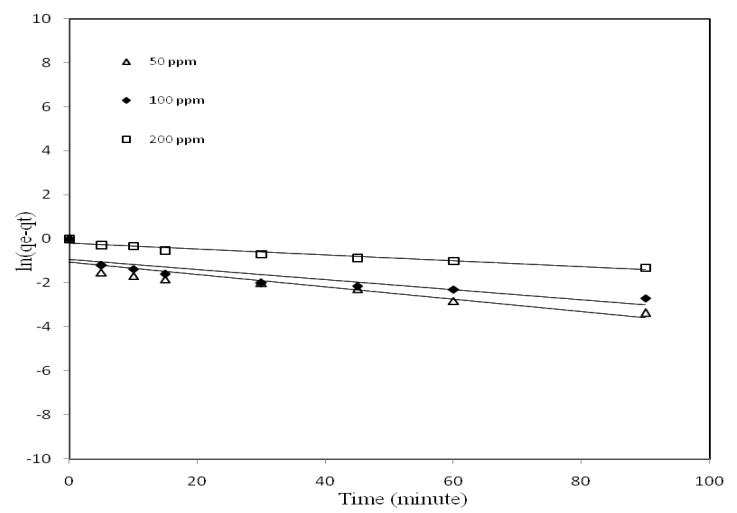

Fig 9: $1^{\text {st }}$ Order Kinetics Analysis of D-R-28 by STWW

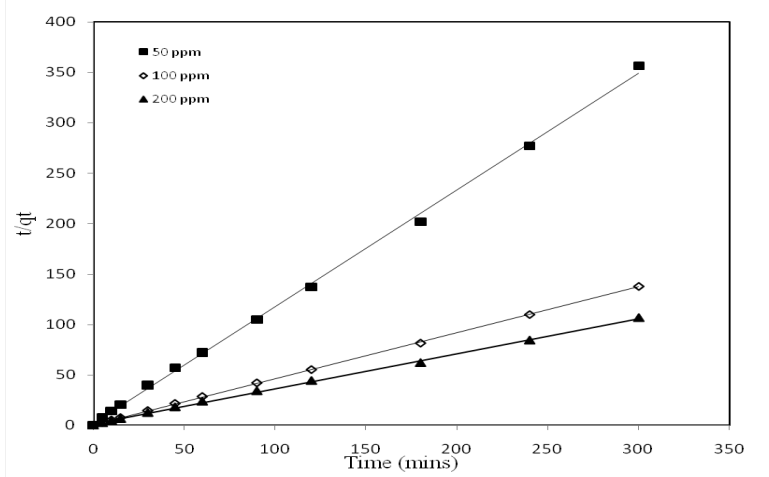

Fig 10: $2^{\text {nd }}$ Order Kinetics Analysis of D-R-28 by STWW

Figure 9 envisages that the value of uptake (qe) lowers down with the raise in D-R-28 concentration. The $\mathbf{1}^{\text {st }}$ order kinetics analysis is demonstrating poorer correlations correspondence values with lower fits. The $2^{\text {nd }}$ order kinetics analysis (Figure 10) of D-R-28 by STWW envisages that the value of uptake (qe) rises with the augmentation in D-R-28 concentration. The correlation correspondence values are in the region of close up to 1 signifying the $2^{\text {nd }}$ order kinetics hysterics fine into the whole laboratory tests system.

\section{Conclusions}

The best possible STWW dosage and stability contact duration for the current research work was identified to be $40 \mathrm{gm} / \mathrm{L} \& 3 \mathrm{~h}$ respectively. Percent confiscation of D-R-28 dye boost up with the raise in STWW dosage up till a convinced range and then relics more or less unvarying. On the other hand, percent confiscation lowers down with the raise in D-R-28 dye concentration. Adsorptive mechanism of D-R-28 dye on STWW is greatest in nature $\mathrm{pH}$ array $(\mathrm{pH}=6.92)$. The graphical isotherm-equilibrium investigation depicts that the Langmuir model is best-most fit model for D-R-28 dye adsorption onto STWW under ideal conditions. The kinetic analysis ensures that the $2^{\text {nd }}$ order kinetic plot is pertinent for the whole progression. For this reason, it could be termed as bestmost fit plot. The utilization of Subabool timber wood waste as a material of sorbent for the dye contaminated wastewater could be another economical option against the other sorption substances or activated carbons. 


\section{References}

[1] Gupta, T.B., and Lataye, D.H. 2018. Adsorption of indigo carmine and methylene blue dye: Taguchi's design of experiment to optimize removal efficiency, Sadhana, Indian Academy of Sciences, 43(170):1-13.

[2] Mohan, D., Kunwar, P. S., and Vinod, K. S. 2008. Waste water treatment using low cost activated carbons derived from agricultural by-products - A case study, J. Hazard. Mater, 152(3): 1045-1053.

[3] Lataye, D. H., Mishra, I. M., and Mall, I. D. 2008a. Adsorption of 2-picoline onto bagasse fly ash from aqueous solution, Chem. Eng. J., 138(1-3): 35-46.

[4] Ingole, R. S., and Lataye, D. H. 2015. Adsorptive removal of phenol from aqueous solution using activated carbon prepared from babu lsawdust, J. Hazard. Toxic Radioact. Waste, 10: 2153-5515.

[5] Srivastava, V., Swamy, M., Mall, I. D., Prasad, B., and Mishra, I. M. 2006. Adsorptive removal of phenol by bagasse fly ash and activated carbon: Equilibrium, kinetics and thermodynamics, Colloids Surf., A Physicochem.Eng. Asp., 272(1-2), 89-104.

[6] Gupta, T.B, and Lataye, D.H. 2017. Adsorption of indigo carmine dye onto acacia nilotica (babool) sawdust activated carbon, J. Hazard. Toxic Radioact. Waste, 21(4): 1-11.

[7] Arami, M., Yousefi, N., Limaee, M., and Mahmoodi Niyaz, M. 2008. Evaluation of the adsorption kinetics and equilibrium for the potential removal of acid dyes using a biosorbent, Chem. Eng. J., 139(1), 2-10.

[8] Langmuir, I. 1918. The adsorption of gases on plane surfaces of glass, mica and platinum, J. Am. Chem. Soc., 40(9), 1361-1403.

[9] Freundlich, H.M.F. 1906. Over the adsorption in solution, J. Phys.Chem., 57, 385-471

[10] Temkin, M. I., and Pyzhev, V. 1940. Kinetics of ammonia synthesis on promoted iron catalyst, Acta Physicochim., 12(1), 327-356.

[11] Gupta, T.B., and Lataye, D.H. Removal of crystal violet and methylene blue dyes using activated carbon of acacia nilotica sawdust, Ind.J. of Chem.Tech, 26: 52-68. 